\title{
Lived Experience of Women with Ischemic Heart Disease (IHD): A Pilot Study on Phenomenology
}

\author{
Praveena K.R. ${ }^{1}$, Sasikumar S. ${ }^{2}$ \\ ${ }^{1}$ Prof., Sree AnjaneyaCollege Of Nursing, Malabar Medical College, Calicut \& PhD Scholar, Yenepoya \\ (Deemed to be University), Mangalore, Karnataka, India, \\ ${ }^{2}$ Professor, Yenepoya Nursing College, Yenepoya (Deemed to be University), Mangalore, Karnataka, India
}

\begin{abstract}
Background: IHD has been regarded as a universal burden. Even though women are sheltered from this dreadful disease during their reproductive years to a certain extent, the incident is almost similar in both genres after menopause. Since women are regarded as the centre of domestic chores in our home settings, any bodily ailments affecting her directly impact thesynchrony of a family.

Aim: This study aimed to describe lived experience of women with IHD to offer a deeper understanding in caregivers, which will help them while taking care of patients and further it will act as a guide to nursing practice.
\end{abstract}

Objective: To explore the lived experiences of women with IHD

Settings and Design: Setting of the study was Malabar Medical College Hospital and Research Centre. Qualitative study, in which descriptive phenomenological design was used for the study.

Materials and Method: The sample of the study included 10 women with Ischemic heart disease who underwent CABG or PTCA from Malabar Medical College Hospital and research centre, Calicut. In depth interviews were conducted within one month to one year of their disease condition. Interviews were recorded and audio files were transcribed. Colaizzi's method was used to direct data analysis and the structure of the phenomenon was formulated.

Statistical Analysis used: N Vivo software version (9) was used for the study.

Results: Significant statements were extracted from the transcribed verbatim and meanings were formulated. Total of seven main themes and several subthemes were emerged; the themes were 1. Pain perception. 2. Fear of impending death. 3. Anxiety 4. Stumbling blocks. 5. Support system. 6. Breakdown the barriers.

Conclusion: The study reflected the pain and sufferings underwent by the patients during the disease process and the factors that helped them for the recovery and their insights to live along with this dreadful disease in their later life.

Keywords: Ischemic heart disease (IHD), lived experience; Phenomenology.

\section{Corresponding Author:}

\section{Sasikumar S.}

Professor, Yenepoya Nursing College, Yenepoya

(Deemed to be University), Mangalore, Karnataka,India

Mobile Number: 9544740811,

e-mail: praveenadileep2001@gmail.com

\section{Introduction}

Ischemic heart disease (IHD) is considered as the leading cause of death in the United States, responsible for 635,260 cardiac deaths in 2016 ${ }^{1}$. Although heart disease is sometimes regarded as a man's disease, almost as many women as men expire each year of heart disease. In spite of the augmented awareness measures taken over the past decades, only about half $(\mathbf{5 6 \%})$ of 
women recognize that heart disease is their number $\mathbf{1}$ killer $^{2,3}$. Considerable amounts of quantitative research are available, which addresses the treatment modalities especially pharmacologic management ${ }^{4}$. Several quantitative studies have also examined the psychological impact of women after a cardiac event ${ }^{5,6}$. However, few qualitative studies were found that address the personal experience of living with this dreadful disease and its subsequent impact on the quality of life of the survivors. A literature review revealed scanty information available on the lived experience of women with IHD even though one study, Moeini ${ }^{7}$ used phenomenology as a method to explore the lived experiences of women. Similar studies could not be found elsewhere which pressured the researcher to take-up this area for the detailed enquiry.

\section{Materials and Method}

A qualitative study, descriptive phenomenological design was used for the study. Sampling adopted was Purposive sampling. In-depth interviews of 10 women who were diagnosed with Ischemic heart disease and underwent either CABG or PTCA with or without stent, and who met the inclusion criteria were selected for the study.

Inclusion Criteria: Patients included were those with Ischemic heart disease who was physically stable and who could speak Malayalam and recall the experiences and had an episode of documented cardiac arrest and survived after hospitalization.

Exclusion Criteria: Patients excluded were those who were diagnosed with psychiatric disorder, organic brain damage or any other co morbidities that could affect their communication and who were not oriented and conscious.

Ethical Considerations: Administrative permission was obtained from Institutional ethical committee, Malabar Medical College Hospital and Research centre. A written informed consent was obtained from the participants.

Procedure for data collection and data analysis: Data were collected at the homes of the Ischemic heart disease (IHD) patients from July 2018 till July 2019. Data collection and data analysis was done simultaneously. To analyze the data Colaizzi's ${ }^{8}$ Phenomenological method was followed. Every sentence and paragraph was scrutinized for extracting significant statements. Formulation of meaning was done by taking each significant statement making sense of it in participants own terms. Hidden meanings were uncovered. The process was repeated for each interview and the data was coded for the emergence of themes. Common patterns were extracted. The data was given for validation and submitted to experts in the field of qualitative research to derive the meanings of each statement. The derived themes and subthemes were discussed with some of the research participants in order to check the validity. Essential themes common to majority of the participants were identified and the structure of the phenomenon was developed.

Statistical Method: N Vivo software version (9) was used for the study.

\section{Results}

The analysis is organized under the following headings

Section 1: Frequency and percentage distribution of sample characteristics

Section 2: Derivation of themes and subthemes

Section 3: Description of phenomenon of lived experience of women with

Ischemic heart disease

Section 1: Frequency and percentage distribution of sample characteristics

\section{Table 1: Frequency distribution of sample characteristics $(n=10)$}

\begin{tabular}{|l|c|c|}
\hline Sample Characteristics & Frequency & Percentage (\%) \\
\hline Age in Years & 2 & 20 \\
\hline $41-50$ & 2 & 20 \\
\hline $51-60$ & 5 & 50 \\
\hline $61-70$ & 1 & 10 \\
\hline $71-80$ & & \\
\hline Religion & 6 & 60 \\
\hline Hindu & 4 & 40 \\
\hline Muslim & & \\
\hline Educational Status & 2 & 20 \\
\hline No formal education & 1 & 10 \\
\hline Primary & 2 & 20 \\
\hline Upper Primary
\end{tabular}




\begin{tabular}{|c|c|c|}
\hline Sample Characteristics & Frequency & Percentage (\%) \\
\hline Secondary & 4 & 40 \\
\hline Graduate & 1 & 10 \\
\hline \multicolumn{3}{|l|}{ Marital Status } \\
\hline Married & 7 & 70 \\
\hline Widowed & 2 & 20 \\
\hline Divorced & 1 & 10 \\
\hline \multicolumn{3}{|l|}{ Occupation } \\
\hline Unemployed & 9 & 90 \\
\hline Professional & 1 & 10 \\
\hline \multicolumn{3}{|c|}{ Associated Medical Condition } \\
\hline HTN & 6 & 60 \\
\hline Diabetes & 6 & 60 \\
\hline Kidney disease & 1 & 10 \\
\hline No other conditions & 1 & 10 \\
\hline \multicolumn{3}{|l|}{ Diagnosis } \\
\hline CAD, TVD & 3 & 30 \\
\hline CAD, DVD & 3 & 30 \\
\hline CAD, Unstable Angina & 2 & 20 \\
\hline CAD, Inferior wall MI & 1 & 10 \\
\hline CAD, Dislipedemia & 1 & 10 \\
\hline \multicolumn{3}{|l|}{ Procedure Underwent } \\
\hline CABG & 2 & 20 \\
\hline PTCA with Stent & 5 & 50 \\
\hline Primary PTCA & 2 & 20 \\
\hline CAG, PTCA & 1 & 10 \\
\hline
\end{tabular}

The data in table 1 shows that majority of the participants were in the age group of 61-70. A greater part $(60 \%)$ of them was Hindus. While considerable numbers (40\%) of the participants had upper primary education, a few $(20 \%)$ did not even have formal education. A majority of the participants were married $(70 \%)$ and a few were widows (20\%). A huge majority (90\%) was unemployed and there was only one professional. With regard to associated medical condition, while equal numbers of participants were affected with both hypertension and diabetes (60\%), a very few (10\%) had Kidney disease. Regarding diagnosis, a considerable number (30\%) are equally affected either DVD or TVD together with CAD. On the topic of procedure underwent, majority $(50 \%)$ had PTCA with stent and very few (10\%) had CAG with PTCA. Patients with CABG and primary PTCA shared an equal number $(20 \%)$.
Section 2: Derivation of themes and subthemes: The purpose of the study was to explore the experience of women with Ischemic heart disease in order to offer a deeper understanding in nurses about the mental agonies of the patients during their disease process which later help them while taking care of patients and it will act as a guide to nursing practice.

1. Perception of Pain: This theme described the physical distresses expressed by the participants during the acute stage of illness. The symptoms varied from mild to severe in intensity. Most of the participants ventilated the worst episode of pain they had experienced.

\section{The Subthemes Were:}

Agonizing Pain: Each participant described the severity of pain differently. Majority of them had said it was unbearable and associated with sweating, headache and breathing difficulty. It started while they are doing some activities. The subtheme could better be understood by the following narration.

Participant A: “...When I reached hospital, there was full of sweat and also I had strangulating pain. They gave me a tablet, then injection and asked me to lie down. The pain was like something kept on my chest; as like I am not able to swallow".

“...Pain started early morning at 4 'O Clock, I went to bathroom came back and lied down. When I was stretching, I felt like some pain from here (Chest) similar to obstructing with something".

Fluctuating Symptoms: The symptoms in the beginning stages were not consistent. Many of the participants had expressed they thought the pain was associated with gas trouble. Also some patients experienced some unusual symptoms such as Jaw pain, tooth pain, syncope and a feeling of block inside them.

Participant A: "That day, while the pain had started I did lots of work and was about to go for cleaning the courtyard of our nearby house (where used to go for household work) ....,I started getting pain, I thought it was gas and had normal medicine for gas trouble, also I had 'Jeera' and water... Later I had one more tablet for gas, but pain did not subside".

Fear of impending death: This theme revealed the inherent fear embedded in the patient during the acute stage of illness. They were aware that this is a 
life threatening disease and had already witnessed some other family members lost their life during the course of illness.

Participant A: I asked how the pain had started during the initial period. She replied "I didn't know it was 'this' pain, so I was not afraid. After knowing this, I thought I may die, anyway my grandfather and all died due to this only.... after the third attack, he had gone.

Anxiety: This theme described the various fears the patients encountered during their disease process. They are mainly the fear of resuming the disease and the anxiety about the future of their loved ones.

Anxiety about future of loved ones: Some of the patients expressed their fear that their absence may affect the future of their children. One of the participant said she had only one daughter and she was anxious about her future. Another participant was not feeling good as her children were not having proper job.

Participant D: .......Regarding hindering factors of recovery, "mainly worries related to recurrence, also thought about daughter, since she is the only child,I should be healthy for taking care of her".

Fear of being burden to the family: This subtheme explains the patients fear that they may be a burden to the family which is evident from their words.

Participant A: “ We cannot stay with children always. Even if they won't mind, others (Daughter in Laws) may not like what we speak at times and that will be difficult. Now I am conscious, later when I am not in my full senses, I don't know what will happen".

Stumbling Blocks: There were various hindering factors that prevented patients from getting a peaceful recovery.

Financial constraints: This subtheme explains the financial difficulties encountered by the patients which prevent them even from seeking medical intervention on time.

Participant A: "Thus we went there (Hospital); they told the operation is "Bypass". Also they asked why you didn't do it from IQURAA. I said the problem was with money. I have no money, my husband had expired".

Mobility Restriction: Few of the participants were finding it difficult to adhere to the imposed restriction in their mobility due to illness.
Participant A: "Now I have one concern I got an elder sister who had cancer, I couldn't travel through bus, so I am not able to visit her often".

Participant D: ....She ventilated her fear of travelling alone. "After this, I have not travelled alone".

Daily Routine Disturbances: This subtheme explains the difficulties experienced by the participants in their day today activities due to disease condition such as resuming her job, social activities, yoga classes etc.

Participant A: "Because of this disease, I could not go for work that I was doing previously. Also I doubt whether I will ever be able to do".

Participant G: "I used to goforyoga, before sickness and was performing almost all "asanas", now I practice only very few of them, others like 'Suryanamaskara' I can't do nowadays".

Support System: This theme explains the support systems available for the participants. They are mainly family, social and spiritual support.

Family Support: This subtheme tries to unveil the help that the participant received from the family members during acute stage of illness. It is seen that all of them had ventilated that they received help from family which aid in a speedy recovery.

Participant A: "My children helped me to come back to normal life. Since they know I couldn't do any work, they only helped for everything. They bring water for bath. I take half cup of water and pour (on my body). She (daughter) used to dry the hair"

"Regarding support, mainly it is my children... I have 6 daughters and one son. My children are staying nearby here".

Social Support: This subtheme tried to explain the support the participants are receiving from the society they live. As we are aware health is not only a physical entity, but also a state of physical, mental and social well being, support from society is very much needed for the speedy recovery of the patients.

Participant B: "Things that helped my recovery; help from my neighbours, not in work, but in terms of their love. There are lots of neighbour's, 10-11 families. Either side of the road, houses are aligned in both sides of the road. All of them were very friendly. They visit 
me often. "Regarding social activities, I am active in Kudumbasree. .... While in competitions, I won't participate for running and jumping, but I will be there to facilitate everything".

Spiritual support: This subtheme tried to explain how faith in god helped the patients to overcome their struggles and it acted as pillar and supported them during their acute stage of illnesses.

Participant A: "We have success and failures in our life. This is because god is testing us (by giving sufferings). This means that we should be more close to god. I even asked doctor whether I can take 'nombu'(Fasting prayer). But he said, I can't as there is tablet to be taken in the afternoon. He suggested putting up with it after completing the medicines. It is like when I borrow some money, I have to repay it to you, similarly, the 'nombu' that are missed once, has to be compensated later".
Learning to cope various ways: This theme tried to describe the various coping strategies adopted by the participants in order to overcome their worries.

Participant J.: "Though I am a person with lots of tension, this time I was courageous. Still I am wondering from where I got that power. Maybe I thought it is for 'me', not for any of the family members. If it is for anyone in the family I would have more concerned. My husband is not as courageous as I am."

Section 3: Description of phenomenon of lived experience of women with

\section{Ischemic heart disease:}

The phenomenon that is emerged out of the analysis of the experience of women with Ischemic heart disease was "To live is to suffer; to survive is to find some meaning in the sufferings".

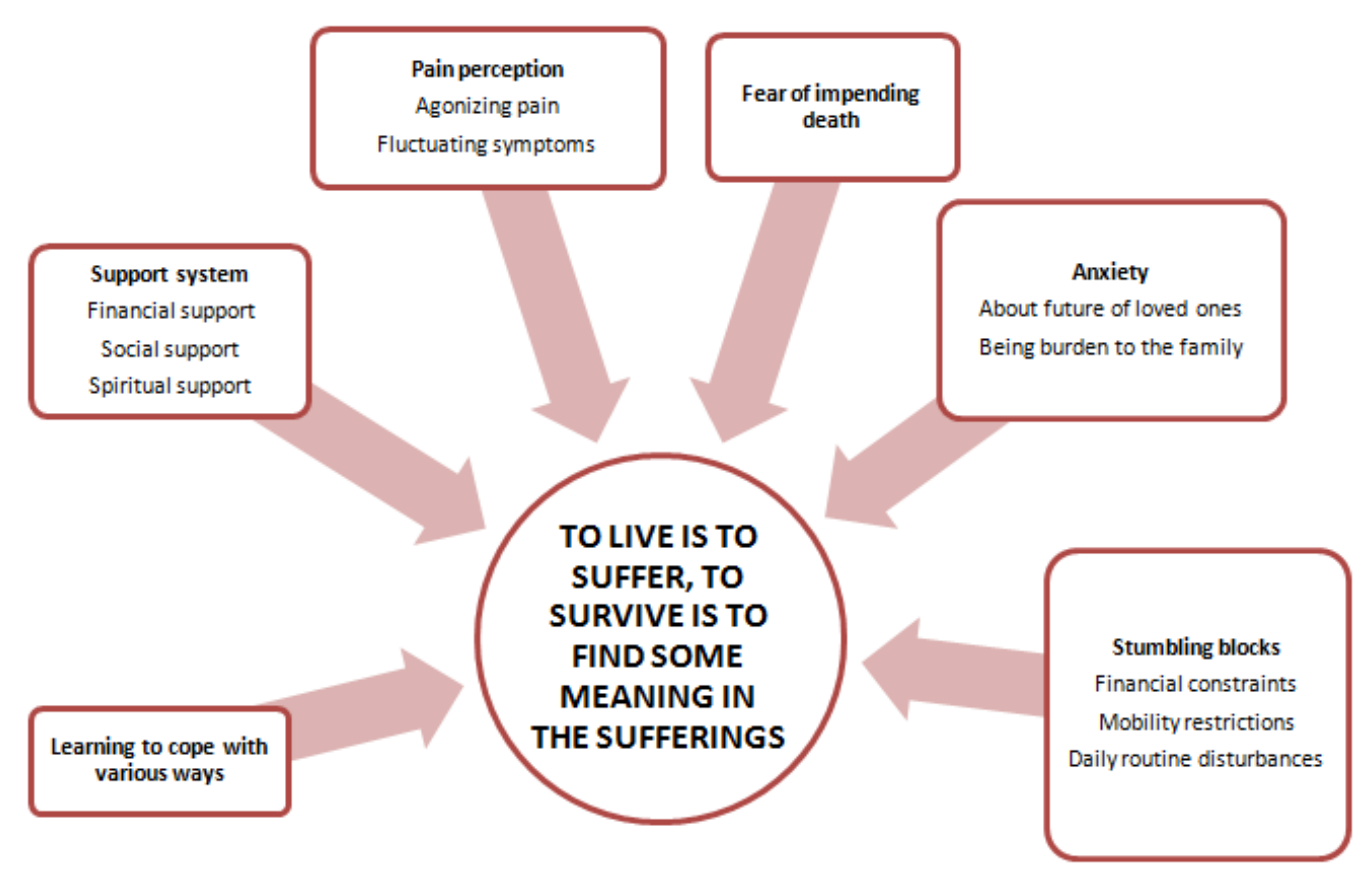

Figure 1. Conceptual model explaining the phenomenon of lived experience of Women with Ischemic Heart Disease

Ischemic heart disease is a life threatening condition both formen and for women. As the women are cornerstone in the family, diseases affecting them will have a great impact in the harmonious functioning of the family. Mostly these women may not be able to resume their role after the disease process. The model in Figure 1 explains the interrelationship of all the themes and subthemes as a closed system connected to each other to form to emerge a phenomenon, "To live is to suffer; to survive is to find some meaning in the sufferings". We cannot distinguish physical and mental agonies separately. They are the collective entity. Living with heart disease is a suffering, but we have to search the ways by which we could cope with these sufferings and lead a life to its maximum potential in the later years of life. 


\section{Discussion}

The study revealed the lived experience of women with IHD as a complex, life changing actuality involving dynamic interplay between physical, psychological, social, spiritual and economic dimensions based upon phenomenology. Even though six themes were described as conceptually distinct, they are not separate entities. But rather, are synthesised with one another in the expressive version of the lived reality. There were several common themes emerged in similar studies. For instance, 'fear of impending death' was described by some other phenomenological studies such as 'lived experience of terminally ill women on home hospice care' ${ }^{9}$ and 'adjusting to a recurring breast cancer' ${ }^{10}$. Other themes such as 'pain perception' was found out in 'a study of Korean women suffering from Rheumatoid arthritis'11 and the theme 'anxiety' in 'spouses of patients with a left ventricular assist device before heart transplantation' 12 . The theme 'Learning to cope with various ways' was found in 'a study of lived experience on patients on dialysis' ${ }^{13}$ and subtheme 'spiritual support' was detailed in a study on 'Spiritual coping mechanisms in chronically ill patients ${ }^{14}$. One of the limitations of this study could be the small sample size which makes the findings difficult to generalize. Sampling adopted for the study was purposive, where randomization is not done, hence couldn't generalize the findings to a wider population. Recommendation could be to conduct a mixed method research which augments the benefits of an integrated approach to strengthen the study.

\section{Conclusion}

With regard to themes, it is understood that having affected with a major cardiac disease is a stressful experience for patients and possess various doubts during the disease process. This necessitates nurses to take effort to address their concerns and prepare them to adjust and adapt to the challenges imposed by the illness and to live a life as fruitfully as possible. Studies describing lived experience of such patients would definitely help nurses to have an insight into their problems and attend their needs effectively.

Acknowledgement: We would like to thank Deputy Director PhD Programme, Former guide and Principal, Doctoral committee members, my colleagues Dr. Deeksha, Dr. Greeni, Yenepoya (Deemed to be University) and Chairman and IEC members, Malabar Medical College Hospital and Research centre, Calicut for their valuable support and guidance.

Conflict of Interest: There is no conflict of interest.

\section{Source of Funding: Self}

Ethical Clearance: Institutional ethics committee approval was obtained from IEC, Malabar Medical College hospital and research centre (No.MMC \& RC/ IEC/2017).

\section{References}

1. Benjamin EJ, Muntner P, Alonso A, Bittencourt MS, Callaway CW, Carson AP, Chamberlain AM, Chang AR, Cheng S, Das SR, Delling FN. Heart disease and stroke Statistics-2019 update a report from the American Heart Association. Circulation. 2019.

2. Gupta R, Mohan I, Narula J. Trends in coronary heart disease epidemiology in India. Ann glob health. 2016 Mar 1; 82(2):307-15.

3. World Health Organization. GlobalStatus Report on Non-Communicable Diseases 2014. Geneva, Switzerland: World Health Organization; 2014.

4. Caricati-Neto A, Errante PR, Menezes-Rodrigues FS. Recent advances in pharmacological and nonpharmacological strategies of cardioprotection. International journal of molecular sciences. 2019 Jan;20(16):4002.

5. Moser DK, Dracup K. Role of spousal anxiety and depression in patients' psychosocial recovery after a cardiac event. Psychosomatic Medicine. 2004 Jul 1;66(4):527-32.

6. Presciutti A, Sobczak E, Sumner JA, Roh DJ, Park S, Claassen J, Kronish I, Agarwal S. The impact of psychological distress on long-term recovery perceptions in survivors of cardiac arrest. Journal of critical care. 2019 Apr 1;50:227-33.

7. Moeini $M$, Naseri N, Zargham-Boroujeni A. Lived experiences of women with ischemic heart disease. Iranian Journal of Nursing and Midwifery Research. 2012 Feb;17(2 Suppl1):S137.

8. Colaizzi, P.F. (1978) Psychological research as a phenomenologist views it. In: Valle, R.S. and King, M., Eds., Existential-Phenomenological Alternatives for Psychology, Oxford University Press, New York, 48-71.

9. Grumann MM, SPIEGEL D. Living in the face of death: interviews with 12 terminally ill women on 
home hospice care. Palliative \& supportive care. 2003 Mar;1(1):23-32.

10. Kenne Sarenmalm E, Thorén-Jönsson AL, GastonJohansson F, Öhlén J. Making sense of living under the shadow of death: adjusting to a recurrent breast cancer illness. Qualitative Health Research. 2009 Aug;19(8):1116-30.

11. Hwang EJ, Kim YH, Jun SS. Lived experience of Korean women suffering from rheumatoid arthritis: a phenomenological approach. International journal of nursing studies. 2004 Mar 1;41(3):239-46.
12. Casida J. The lived experience of spouses of patients with a left ventricular assist device before heart transplantation. American Journal of Critical Care. 2005 Mar;14(2):145-51.

13. Clarkson KA, Robinson K. Life on dialysis: a lived experience. Nephrology Nursing Journal. 2010 Jan $1 ; 37(1)$.

14. Narayanasamy A. Spiritual coping mechanisms in chronically ill patients. British journal of Nursing. 2002 Dec 12;11(22):1461-70. 